comparison of Brazilian CS mortality with data from other international databases.

\section{References}

1. Reddy KS, Yusuf S. Emerging epidemic of cardiovascular disease in developing countries. Circulation. 1998;97:596-601.

2. Leao BF, Bernardes MM, Levin J, Moura L, Bandarra E, Modesto LM, et al. The Brazilian National Health Informatics Strategy. Medinfo. 2001;10(Pt 1):38-42.
3. Society of Cardiothoracic Surgeons of Great Britain and Ireland. National Adult Cardiac Surgical Database Report 2000-2001. Available at: http://www.scts.org. Accessed: May, 29, 2005.

4. The Society of Thoracic Surgeons. STS Adult CV Surgery National Database. Fall 2004 Executive Summary contents. Available at: http://www.ctsnet.org/file/STS-ExecutiveSummary-Fall2004.pdf. Accessed: May, 29, 2005.

5. Reis AAC, Nascimento CAL, Ribeiro ALP, Daher CV, Costa HS, Nogueira JLS, et al. Política Nacional de Atenção Cardiovascular de Alta Complexidade. Brasília: Ministério da Saúde; 2004. p. 125 .

\title{
Simultaneous removal of an Amplatzer device from an atrial septal defect and the descending aorta
}

\author{
Kristine Teoh, FRCS, ${ }^{a}$ Emma Wilton, MRCS, ${ }^{\text {a }}$ Stephen Brecker, FRCP, ${ }^{\mathrm{b}}$ and Marjan Jahangiri, FRCS, ${ }^{\text {a }}$ \\ London, United Kingdom
}

$\mathrm{T}$ The Amplatzer Septal Occluder (ASO; AGA Medical) has been in clinical use since $1996^{1}$ and is associated with few complications and excellent short-term and midterm results. $^{2}$ We report a case of late embolization of an ASO into the descending thoracic aorta, which was managed surgically by means of simultaneous device retrieval from the descending aorta and atrial septal defect (ASD) closure through a median sternotomy.

\section{Clinical Summary}

A 37-year-old woman was investigated for recurrent symptoms after previous successful transcatheter closure of a complex secundum ASD. She had presented 4 years previously with palpitations, dizzy spells, and blackouts. On that occasion, she was given a diagnosis of 2 secundum ASDs. These were closed percutaneously in December 2002 with 2 ASOs with diameters of 16 and $13 \mathrm{~mm}$, respectively. These 2 ASOs were deployed in an interdigitating fashion. The devices were stable to provocative maneuvers, and postprocedure echocardiography revealed only a trivial residual shunt. Up to 18 months' follow-up, the patient remained asymptomatic with a small residual shunt. Two years after device placement, however, she presented with recurrent palpitations and symptoms of nocturnal dyspnea. Repeat echocardiography revealed a recurrent ASD below the previous closure. After coun-

From the Departments of Cardiothoracic Surgery a and Cardiology, ${ }^{\mathrm{b}}$ St George's Hospital, London, United Kingdom.

Received for publication Nov 28, 2005; accepted for publication Dec 9, 2005.

Address for reprints: Marjan Jahangiri, FRCS, Department of Cardiothoracic Surgery, St George's Hospital, Blackshaw Rd, London SW17 0QT, United Kingdom (E-mail: marjan.jahangiri@stgeorges.nhs.uk).

J Thorac Cardiovasc Surg 2006;131:909-10

$0022-5223 / \$ 32.00$

Copyright $\odot 2006$ by The American Association for Thoracic Surgery doi:10.1016/j.jtcvs.2005.12.030

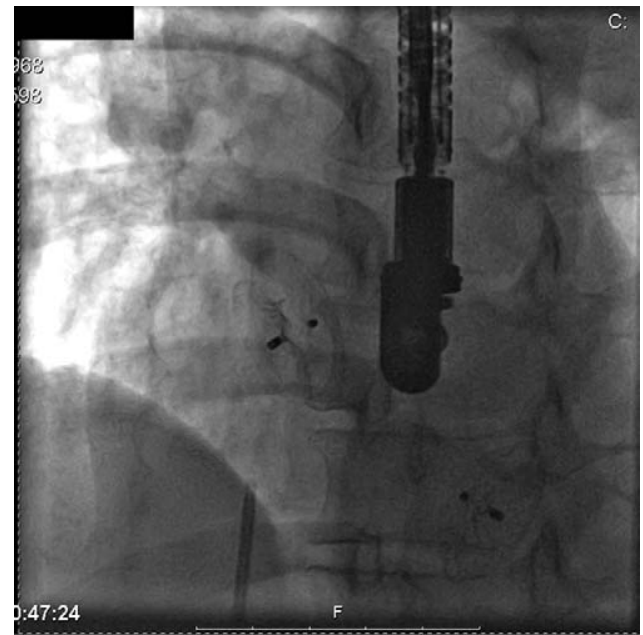

Figure 1. Radiograph demonstrating Amplatzer devices in the atrial septum and descending aorta, with a transesophageal echocardiographic probe in the esophagus.

seling regarding the alternatives of repeat transcatheter closure or surgical intervention, the patient elected to proceed with device closure. Her ensuing transesophageal echocardiogram and on-table radiographic screening revealed an embolized ASO (the 13-mm device) in the descending aorta (Figure 1). Transcatheter closure was therefore abandoned, and the patient was referred for surgical closure of her residual ASD and retrieval of the embolized ASO. Preoperative computed tomographic scanning confirmed the location of the ASO in the descending aorta just above the diaphragm (Figure 2). The operation was performed through a median sternotomy to avoid a staged procedure.

Cardiopulmonary bypass was established by using ascending aortic and femoral arterial cannulation and bicaval cannulation. 


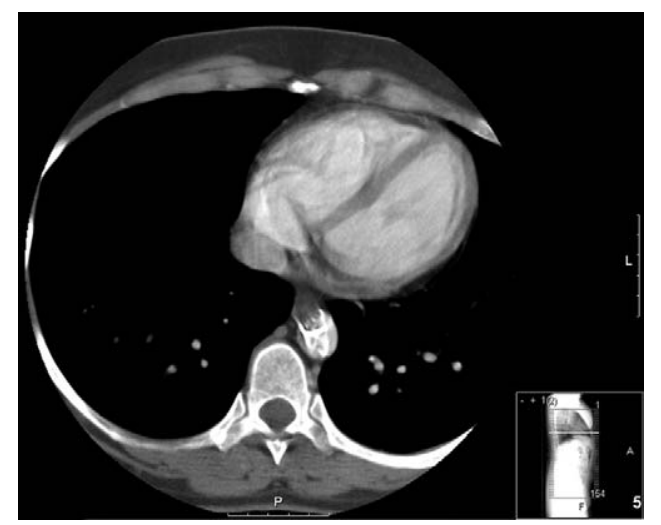

Figure 2. Computed tomographic scan image of an Amplatzer device in the descending aorta.

After antegrade cold blood cardioplegic arrest, the heart was retracted cranially to allow access to the posterior pericardium, which was opened to expose the lower descending aorta. The ASO was located by using epiaortic scanning. At aortotomy, between 2 clamps the ASO was found to be well epithelialized and densely adherent to the intima of the descending aorta. It was removed intact, and the aortotomy was closed directly. ASD closure was performed through a right atriotomy by using an autologous pericardial patch after excision of the remaining ASO from the atrial septum. The patient made an uncomplicated postoperative recovery.

\section{Discussion}

The reported incidence of early device embolization after transcatheter ASD closure with the ASO is approximately $0.5 \%,{ }^{3}$ whereas late displacement and migration is rare. ${ }^{4}$ When a device has migrated early, percutaneous retrieval is a well-established technique. ${ }^{3}$ In this case, however, the diagnosis of late ASO embolization raised the possibility of endothelialization of the device and the risk of injury to the descending aorta should percutaneous device retrieval be attempted. This cautious approach was mitigated by the operative findings, where the device was found to be well embedded in the descending aorta.

Regarding the surgical challenge that this particular case presented, the presence of an intracardiac lesion in combination with a descending aortic lesion requiring surgical attention is unusual. Although it would have been reasonable to address the 2 conditions through 2 separate incisions, the higher morbidity and mortality associated with staged procedures was undesirable. We have successfully adapted a strategy used in coarctation repair, ${ }^{5}$ which permitted both the repair of the ASD and the retrieval of the ASO device from the descending thoracic aorta through a single incision. In addition, the use of epiaortic scanning to precisely locate the device is a solution to an uncommon problem.

\section{References}

1. Chan KC, Godman MJ, Walsh K, Wilson N, Redington A, Gibbs JL. Transcatheter closure of atrial septal defect and interatrial communications with a new self expanding nitinol double disc device (Amplatzer septal occluder): multicentre UK experience. Heart. 1999;82:300-6.

2. Yew G, Wilson NJ. Transcatheter atrial septal defect closure with the Amplatzer septal occluder: five-year follow-up. Catheter Cardiovasc Interv. 2005;64:193-6.

3. Levi DS, Moore JW. Embolization and retrieval of the Amplatzer septal occluder. Catheter Cardiovasc Interv. 2004;61:543-7.

4. Chessa M, Carminati M, Butera G, Bini RM, Drago M, Rosti L, et al. Early and late complications associated with transcatheter occlusion of secundum atrial septal defect. J Am Coll Cardiol. 2002;39: 1061-5.

5. Morris RJ, Samuels LE, Brockman SK. Total simultaneous repair of coarctation and intracardiac pathology in adult patients. Ann Thorac Surg. 1998;65:1698-702. 